\title{
CREATE DIGITAL GAMES FOR EDUCATION: GAME DESIGN AS A TEACHING METHODOLOGY
}

\author{
T. Wernbacher ${ }^{1}$, R.A.P. Reuter ${ }^{2}$, N. Denk ${ }^{1}$, A. Pfeiffer ${ }^{1,3}$, N. König ${ }^{1}$, \\ K. Fellnhofer ${ }^{4,5}$, A. Grixti ${ }^{5}$, S. Bezzina ${ }^{6}$, E. Jannot ${ }^{7}$ \\ ${ }^{1}$ Danube University Krems (AUSTRIA) \\ ${ }^{2}$ University of Luxembourg (LUXEMBOURG) \\ ${ }^{3}$ Massachusetts Institute of Technology (UNITED STATES) \\ ${ }^{4}$ ETH Zürich (SWITZERLAND) \\ ${ }^{5}$ Research and Innovation Management GmbH (AUSTRIA) \\ ${ }^{5}$ Malta Information Technology Agency (MALTA) \\ ${ }^{6}$ Ministry for Education and Employment (MALTA) \\ ${ }^{7}$ University of Applied Sciences Europe (GERMANY)
}

\begin{abstract}
Besides the pure application of serious games as tools for knowledge transfer, a further trend has been observed in the last few years: The creation of games as an opportunity to gain practical experience and thereby also build up valuable knowledge. In this context several approaches are possible, such as using paper prototyping, game maker tools like Scratch, RPG-Maker, Construct 3 or Game Maker Studio 2, and the application of actual game engines like Unity. This contribution aims to discuss the possibility of creating games in a very specific, predefined genre using game maker tools that have been especially developed for use in an educational context and therefore offer didactic guidance. The Game Creator Tool which was developed as part of the Erasmus+ project Create Digital Games for Education (CDG4E) is presented in more depth. Using this tool, one can create decision card games inspired by the mobile game bestseller "Reigns". Within the project, the consortium created educational games in different areas such as fake news prevention and STEM education. In addition to these ready-made games, another focus was placed on using the tool itself as a teaching technique, for example to create games on a specific topic with school classes or within youth work, but also as an instrument for setting up dedicated "game jams". This contribution reports on the advantages and drawbacks of creating the tool itself by analysing qualitative and quantitative data gathered during the iterative design process of the Game Creator.
\end{abstract}

Keywords: Game Creation, Game-based Learning, Gamification, STEM Education, Fake News Prevention.

\section{INTRODUCTION}

Digital games in the form of serious games on the one hand, or commercial games with didactic guidance on the other, have a highly positive influence on the lessons in the classroom, after-school care or leisure activities. Gamification, if used in a proper way, can also achieve motivational effects in education. However, a potentially very strong use of the topic of play and games in education is still widely underrated in the literature and in applied projects: the use of game design as a teaching method and especially the role of students as educational game designers (see related work). The aim of this paper is to address this particular topic.

Teaching methods, centred around (digital) game creation, offer a lot of educational potential. This ranges from conceptional game design, the creation of paper prototypes and the development of game content to the actual programming of a game. In this way, on the one hand, creativity and STEM skills can be promoted; on the other hand, such creation of games also involves dealing with the game content. In this way, game design can basically become part of a teaching method in connection with all subject areas and can also be used in a cross-curricular manner. Thanks to different tools, the development of digital games in an educational context does not necessarily require elaborate programming skills. A popular example is "Scratch" [1], which allows the creation and online sharing of interactive stories, games and animations. "Twine" [2] is another free software for easy development of text-based adventures, while "Pocket Code" [3] enables game programming directly from the smartphone. 
Within the framework of an Erasmus+ Strategic Partnership, the consortium ${ }^{1}$ has also developed a Game Creator Tool [4] (here referred to as the "CDG4E Game Creator"). While many of the existing game creators give a lot of freedom concerning the implementation of game mechanics, the CDG4E Game Creator provides the basic game mechanics and therefore implies a certain didactic design. At the same time, it leaves the freedom to create games for different educational topics. This enables teachers as well as students to create games for various teaching contents with a low-threshold introduction and no programming or design skills required. Another key feature of the creator is that it was specifically designed to empower students to create educational games that go beyond a simple quiz mechanism. The CDG4E Game Creator can be accessed free of charge via https://www.wazagames.com/gamecreator.

This paper describes the methods of the iterative development of the CDG4E Game Creator and introduces the tool itself, its underpinning didactic framework, as well as the results from the evaluation.

\section{RESEARCH QUESTIONS}

The guiding research questions of the Erasmus+ project "Create Digital Games for Education" are:

- How does a Game Creator look like in order to a) empower both students and teachers to create educational games on complex topics, b) be easy to use without programming skills and c) embed a didactic design directly in the game mechanics?

- What requirements do students and teachers have for such a tool?

- How is the CDG4E Game Creator rated in terms of usability and educational value?

- Can the pilot games induce subjective knowledge transfer effects in terms of enhanced media literacy skills?

- Can subjective changes in students' interest and in their motivational engagement be observed after playing the pilot games?

\section{METHODOLOGY}

Following a desktop review approach, the authors evaluated the literature on existing solutions and discussions on the topic of game-based learning, gamification in the educational sector and using game design as educational method. We analyzed different game design tools that do not require specific programming skills (see related work).

The quality of the projects' results was measured in course of a formative (quality assurance sessions) as well as a summative evaluation which focused on cognitive as well as motivational effects. Following an iterative design method, we ensured a good fit to the target groups' needs by involving them in early developmental stages. The aim of the summative evaluation was to assess the usability, the perceived educational value as well as the impact of two pilot games and of the CDG4E Game Creator.

\section{RELATED WORK}

In the following we would like to present essential literature in the field of (educational) game design, preliminary research by the authors, and papers in the field of game design as an educational method. Furthermore, we will address game creator tools, which do not require any previous programming knowledge and are suitable for educational game design methods in class.

\footnotetext{
${ }^{1}$ The consortium consists of: Lead: Malta Information Technology Agency (Digital Outreach); Partners: Danube University Krems (Center for Applied Game Studies); waza! UG, University of Luxemburg (Department of Education and Social Work); Science Centre Pembroke Malta; Research and Innovation Management GmbH
} 
Table 1. Related work

\begin{tabular}{|c|c|}
\hline Authors & Context \\
\hline \multicolumn{2}{|l|}{ Essential literature } \\
\hline C. Fernandez-Vara (2014) [5] & $\begin{array}{l}\text { The book "Introduction to Game Analysis" serves as an accessible guide to } \\
\text { analysing games using strategies borrowed from textual analysis. }\end{array}$ \\
\hline T. Fullerton (2014) [6] & $\begin{array}{l}\text { The book "Game Design Workshop: A Playcentric Approach to Creating } \\
\text { Innovative Games" demystifies the creative process with clear and } \\
\text { accessible analysis of the formal and dramatic systems of game design. } \\
\text { Using examples of popular games, illustrations of design techniques, and } \\
\text { refined exercises to strengthen your understanding of how game systems } \\
\text { function and give you the skills and tools necessary to create a compelling } \\
\text { and engaging game. }\end{array}$ \\
\hline J. Schell (2014) [7] & $\begin{array}{l}\text { "The Art of Game Design" (book) presents 100+ sets of questions, or } \\
\text { different lenses, for viewing a game design, encompassing diverse fields } \\
\text { such as psychology, architecture, music, visual design, film, software } \\
\text { engineering, theme park design, mathematics, puzzle design, and } \\
\text { anthropology. }\end{array}$ \\
\hline K. Salen [8] & $\begin{array}{l}\text { Written for game scholars, game developers, and interactive designers, } \\
\text { "Rules of Play" is a textbook, reference book, and theoretical guide. It is the } \\
\text { first comprehensive attempt to establish a solid theoretical framework for the } \\
\text { emerging discipline of game design. }\end{array}$ \\
\hline J. Linderoth, B. Sjöblom [9] & $\begin{array}{l}\text { The paper "Being an Educator and Game Developer: The Role of } \\
\text { Pedagogical Content Knowledge in Non-Commercial Serious Games } \\
\text { Production" discusses the need for people with pedagogical content } \\
\text { knowledge AND knowledge about game development in the field of game- } \\
\text { based learning. }\end{array}$ \\
\hline
\end{tabular}

Related research projects from the authors and their institutions

N. König, A. Pfeiffer, T.

Wernbacher, N. Denk (2020) [10]

N. König, A. Pfeiffer (2020) [11]

N. Denk, A. Pfeiffer, T. Wernbacher, V. Camilleri (2015) [12]

N. König, A. Pfeiffer, T. Wernbacher (2014) [13]

Denk, N.; Pfeiffer, A.;

Wernbacher, T.; Ertl, B., Röhsner, U. (2016) [14]
The chapter "Game-Based Learning Research at the Danube University Krems' Center for Applied Game Studies" gives insights on more than a decade research on the topic of game based learning in the educational sector at Danube-University Krems and describes preliminary projects, which among other aspects have formed the basis for the project described in this paper. For instance, the Toolkit Game-based learning, to name one explicitly.

The contribution "Outputs and Insights From 12 Years of Game-Based Learning Research at the Danube-University Krems' Center for Applied Game Studies" gives a detailed outlook on future projects in the field involving the center for applied game studies, especially in regards to approaches with different self-developed game-maker tools.

The chapter "Game Based Learning to Alleviate Early School Leaving" Weiterentwicklung der Toolkit-GBL Plattform, zur Verringerung der Schulabbruchsquote in Malta und Schweden" gives detailed insights into the project "toolkit-gbl.com".

The paper "Gaming Media and Their Application in Educational Practice: An Interactive Toolkit for Teachers" describes the needed categories to create a meaningful didactic framework accompanying game-based learning approaches in school and youth work.

The paper "A Social Network Game for Encouraging Girls to Engage in ICT and Entrepreneurship - findings of the project MIT-MUT" presents the results of the implementation and evaluation of a social network game, where, amongst other things, paper prototyping was introduced as a design method in class. 


\begin{tabular}{l|l}
\hline \hline Specific literature on game-design as educational method \\
\hline M. Overmars (2004) [15] & $\begin{array}{l}\text { The paper from Overmars titled "GAME DESIGN IN EDUCATION" concludes } \\
\text { that "creating games appeals to all ages and to both males and females. It } \\
\text { involves a lot more than programming, bringing together aspects of liberal arts, } \\
\text { mathematics, social sciences and computer science. By using game design in } \\
\text { an educational context you create an enthusiastic group of students that are } \\
\text { eager to learn and who will find out that creating games can be even more fun } \\
\text { than playing them." The author used the tool "Game Maker" for his project. } \\
\text { Especially remarkable is the early approach of Obermars. As early as 2004 the } \\
\text { project was initiated. }\end{array}$ \\
\hline M. Ahmad (2019) [16] & $\begin{array}{l}\text { In the book chapter titled "Categorizing Game Design Elements into Educational } \\
\text { Game Design Fundamentals" analyses game design elements discussed over } \\
\text { the past decade and intends to group them onto established fundamental } \\
\text { elements. }\end{array}$ \\
\hline P. Tan (2010) [17] & $\begin{array}{l}\text { The short paper "Iterative game design in education" looks into challenges in } \\
\text { regards to the method of iterative game design and proposes some potential } \\
\text { solutions for introducing this principle in a higher education context. }\end{array}$ \\
\hline T. Bjoerner, C. B. Søgaard & $\begin{array}{l}\text { The paper "Designing an Educational Game: Design Principles from a Holistic } \\
\text { Perspective" suggest design principles for educational games, and to integrate } \\
\text { teachers, pupils and game designers needs and requirements. To set up these } \\
\text { design principles for educational games the authors have used a holistic } \\
\text { perspective. This means that the design principles must be seen in coherence } \\
\text { within the social and physical environment. }\end{array}$ \\
\hline
\end{tabular}

\begin{tabular}{l|l}
\hline Selection of Game Creator tools, besides professional game engines: \\
\hline Scratch [1] & $\begin{array}{l}\text { Is a free to use block-based visual programming language and online } \\
\text { community where you can create your own interactive stories, games, and } \\
\text { animations. The main target group are children and the use in the educational } \\
\text { context. It has been developed at MIT. }\end{array}$ \\
\hline RPG Maker [19] & $\begin{array}{l}\text { RPG Maker is a series of tools for developing classic role-playing games. The } \\
\text { tool is available on STEAM and the licencing costs make it affordable as a great } \\
\text { tool to get into the topic of story-driven game development. }\end{array}$ \\
\hline Construct 3 [20] & $\begin{array}{l}\text { Construct is an HTML5-based 2D game editor, developed by Scirra Ltd. It is } \\
\text { aimed primarily at non-programmers, allowing quick creation of games through } \\
\text { visual programming. Licencing for a classroom is currently available for } \\
\text { approximately 30 Euro per year. }\end{array}$ \\
\hline Game Maker Studio 2 [21] & $\begin{array}{l}\text { Game Maker Studio 2 is a tool with the aim to create 2D games. Game Maker is } \\
\text { intended to give designers the possibilities to create professional 2D games. } \\
\text { The Educational Version cost 50 Euro per seat each year. }\end{array}$ \\
\hline
\end{tabular}

\section{RESULTS}

In the following, the CDG4E Game Creator and usage scenarios are described in detail, based on the results and experiences of the research project. Furthermore, the central results of the evaluation are explained.

\subsection{CDG4E Game Creator}

The CD4E Game Creator was developed within an iterative design process, including both teachers and students from Malta, Austria, Luxembourg and Germany. In this section we describe the final product.

\subsubsection{Game mechanics and didactical framework}

Within the CDG4E Game Creator the basic game mechanics are predefined, which on the one hand simplifies the game creation considerably, and on the other hand a certain didactic design can already be incorporated. This is intended to encourage a reflective approach to a topic. Following the example of the popular mobile game "Reigns" [22] (Devolver Digital, 2016), decisions and their effects on "resources" are the focus of the game mechanics. The CDG4E Game Creator's editor is used to create different "cards" in the course of game creation, which pose challenges or questions to the players. In addition, two decision options are defined, and it is determined how and whether the 
respective decisions change the values of previously defined resources. Depending on the settings, the cards are presented in the game in random or linear order and it is possible to create games in different levels of complexity. The essential feature of this game mechanic is that - unlike a classic quiz, for example - it is not about answering a question right or wrong. Rather, it is about dealing with the effects of the decisions and being aware that your actions in the game can have consequences.

The possibilities offered by this game mechanism are manifold. Basically, games can be created for any teaching topic. However, the greatest potential lies in the mediation of more complex topics, where the understanding of systems and contexts is central. Examples of this are topics related to media competence, ethics, society or environmental education. However, the goal here should not and cannot be to convey a complex topic completely directly in the game. Rather, the games can be used to stimulate discussion, as a starting point for opening a subject or to provide in-depth information on a subject area. As always with the use of games in class, the didactic method and the guidance of the teacher is crucial.

A great educational potential lies in projects with the CDG4E Game Creator that put students in the role of educational game designers. Guided by the integrated game mechanics, in the process of the game development students deal with questions like: What is the role of the player? From which perspective should the decisions be made? What resources are represented in the game? What actions can be taken? Which decisions are to be made by the players? How should the decisions affect the available resources? In this way students (as game designers) need and gain a deep understanding of a topic in order to create a game.

Within the research project we developed and tested games on two topics: Fake News and STEM Education. As a simple game mechanic that works both for students as players and students as designers, we outlined the following approach on the theme of Fake News. Players take on the role of a social media manager and have to decide which posting they publish. Each card that comes into play represents a new posting. Within the game players either "publish" or "reject" the posting. The decisions have an impact on the value of four predefined "resources", which are "Popularity", "Credibility", "Conscience" and "Influence". The game ends if a) when one or more resources have reached a certain value or b) all cards have come into play. Depending on the achieved value of the resources, different end cards are shown, which may describe a winning or losing situation. This game mechanic encourages players to think ahead, as every decision can affect one or more resources in the game. But also, when creating the content for the playing cards (that represent in this case the social media content), a lot of reflection and understanding of the respective game topic is required ${ }^{2}$.

\subsubsection{Game editor}

The CDG4E Game Creator is developed with Unity and can be accessed online via the web browser at https://www.wazagames.com/gamecreator/. Furthermore, the games can be accessed via an app on android smartphones (provided via an APK file). In the tool users can either download and play games created by the consortium or by the community, which is useful if one wants to use a game within a game-based learning method on a specific topic. Users can also use the editor to create their own game on the topic of their choice. The latter is in fact the main intention of the tool.

Two modes can be selected when creating the games. In the "Random" mode, cards are randomly shown during gameplay. "Conditions" ("Play this card when...") can be used to exclude or trigger certain cards in relation to a certain resource value. In the "Story" mode you can specify the order in which the cards are to be played but you can also use random cards. Additionally, you can use "flags" (true/false) to trigger or exclude cards from the stack. The resources are always displayed at the top of the screen during gameplay. Each resource has a start value, a maximum and a minimum value. For each card you can define if and how the player's decisions affect the respective resources.

This structure empowers people to create games of varying levels of complexity. In the creation of games, the premise often associated with playing games per se is "easy to learn, hard to master".

\subsubsection{Screenshots}

The following is a gallery of screenshots from the CDG4E Game Creator :

\footnotetext{
2 A game-based learning method, centred around this approach is published on the TOOLKIT platform: https://toolkitgbl.com/projects/539
} 


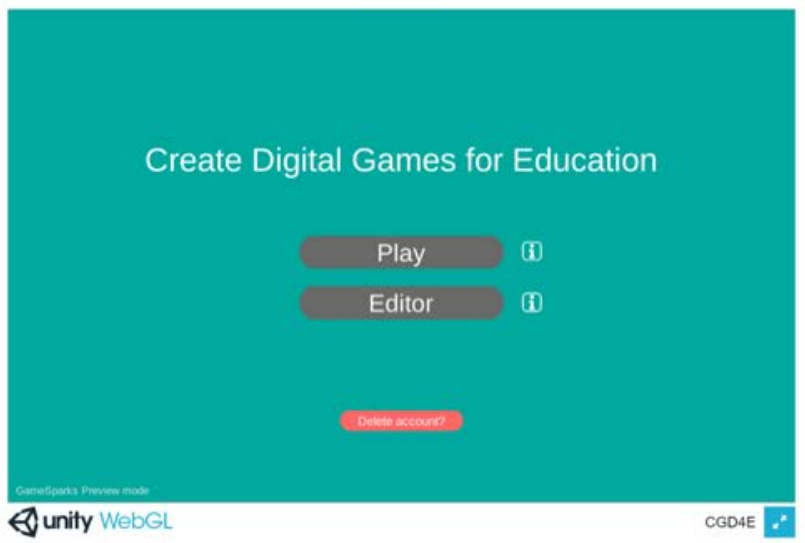

Figure 1. Selection of either playing an existing game or using the editor.

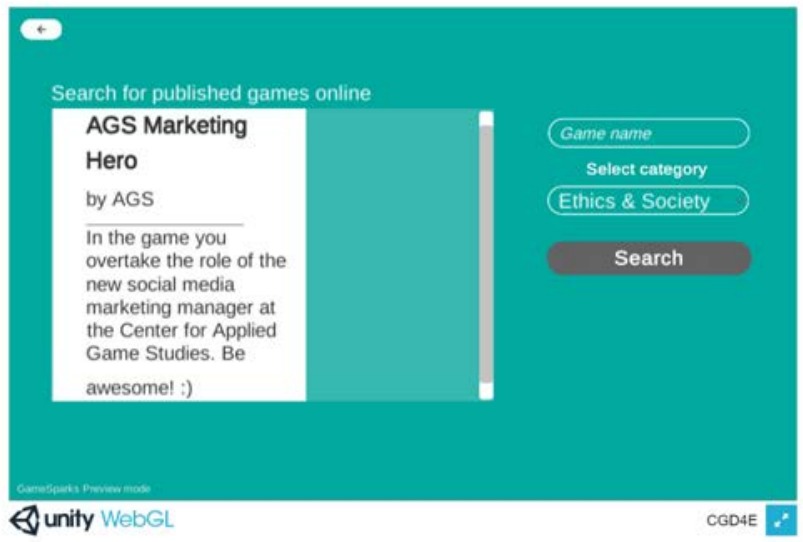

Figure 2. Clicking on 'Play' gives the player the option to search for a game within a specific category.

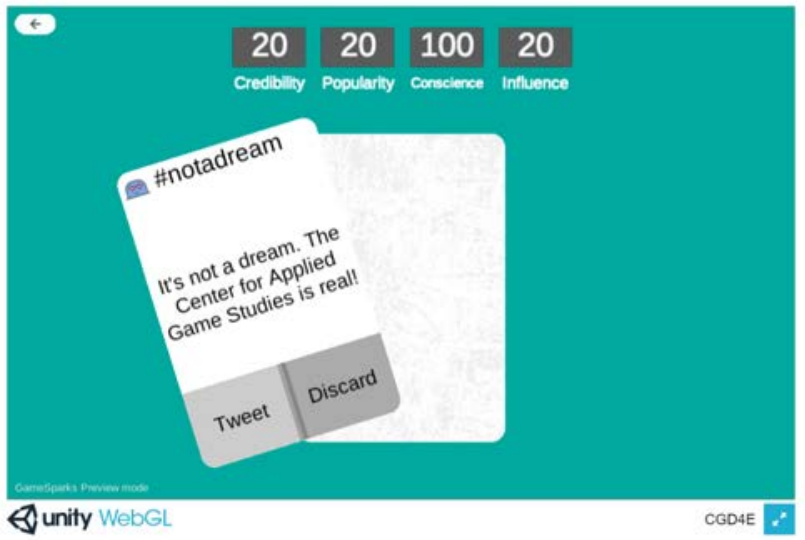

Figure 3. Gameplay: In this example the player acts as the social media manager of a university. 


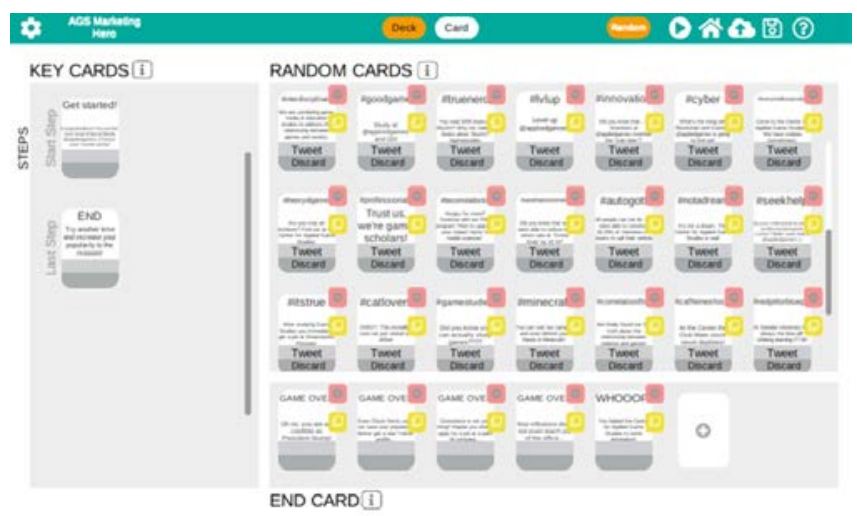

Figure 4. The editor in "Random Mode".

\subsection{Evaluation of the CDG4E Game Creator: key findings and learnings}

In this section insights on the qualitative and quantitative data gathered during the field tests are reported. The method applied relied on a post-test. Quantitative multiple-choice items (5 point Likert scale) and open questions were part of the online survey. In total 4 teachers \& 86 students participated. As an instruction standardized GDPR compliant privacy statements as well as an introduction into the 2 pilot games were given out.

\subsubsection{Quantitative Results}

For students the overall rating of the CDG4E Game Creator is positive with means ranging from 2,16 to 3,59 . Critical remarks referred to the navigation within the Game Creator as well as the overall usability when using the Game Creator for the first time. The two pilot games (relating to Fake News and STEM Education) were also received well within the target group with means ranging from 1,90 to 2,59 on a 5 point Likert scale (low values are equal to a high level of agreement).

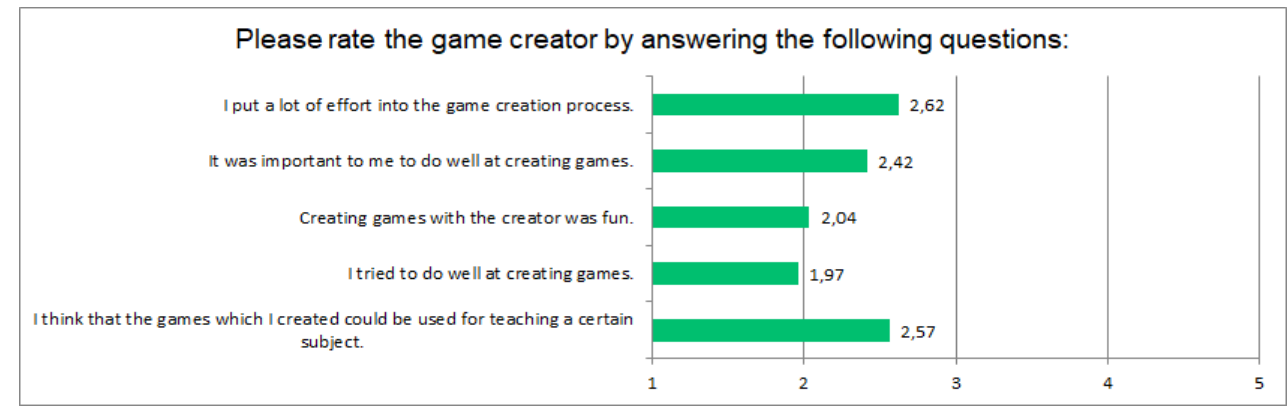

Figure 5: Quantitative feedback on the game creation process

The game creation process itself was perceived positively with high values reported for motivational engagement and interest (means ranging from 1,97 to 2,62) in reference to the games created.

With regard to the topics addressed within the pilot games media literacy is seen as an important competence by students ( $M=1,90$ on a 5 point Likert scale) while STEM-related learning materials are seen as relevant for future professions $(M=2,5)$. There is a high level of reported interest for subjects where media literacy was addressed with means ranging from 2,01 to 2,35. Students stated that they now have a good understanding of this topic after playing the pilot game relating to fake news $(M=2,01)$. The motivational engagement in STEM-related subjects was high after students played the respective pilot game with means staying below 2,5.

For teachers the overall rating of the Game Creator Tool ( $M=3,5$ on a 5 point Likert scale) is more critical in comparison to the students. Especially usability related aspects give room for improvements. 


\subsubsection{Qualitative Results}

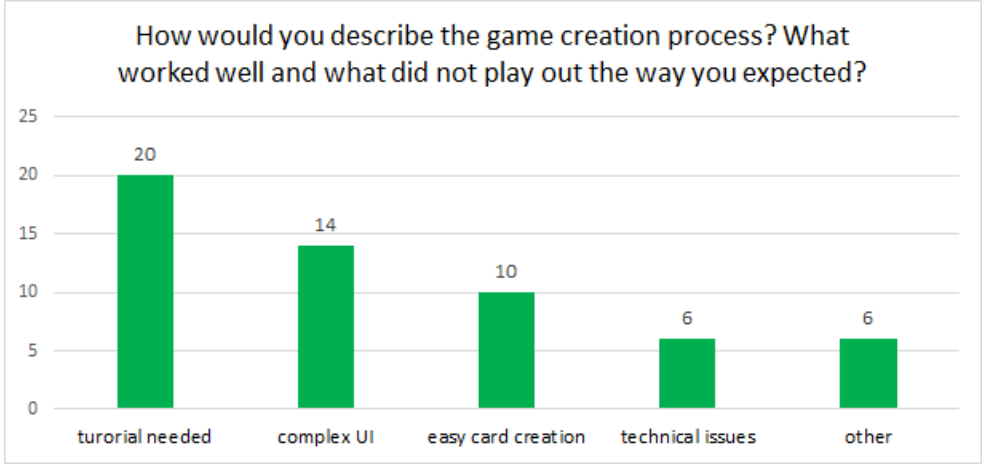

Figure 6: Qualitative feedback on the game creation process

Remarks on the game creator by students show that a tutorial is highly needed because of the complex user interface ( $20 \%$ of total statements based on a content analysis) - especially for first time users.

A similar picture emerges in the statements of the teachers: "If the user interface of the whole platform is improved, I would consider using such a tool" and the game creation process "More time could have been invested in creating the game". Regarding the pedagogical potential teachers stated that the games are "Interesting and motivating, whether to stimulate discussion (Fake News) or to acquire knowledge (Science Safari)."

The UX issues mentioned by both target groups have already been fixed by the consortium and a tutorial was developed and is now available.

\section{CONCLUSIONS}

Based on the distinction between educational technology integration strategies, namely using ICT to support directed instruction or to support inquiry-based learning, we can distinguish here between two main pedagogically meaningful uses of the CDG4E Game Creator and the games that can be produced with it. Students can equally learn by both playing games and creating games. It is also possible to combine these two approaches: first play a game, uncover the implemented mechanics and causal relations, then evaluate them against a realistic model of the phenomenon at hand and finally revise or expand the game for it to become a better model of the studied phenomenon.

While playing games students can actively engage with a learning situation created by their teacher (or another student), where some phenomena are discoverable. Furthermore, when creating, extending or revising a game, students are required to show their own understanding of some realworld or imaginary phenomenon and apply that to construct a digital artefact that others can interact with.

Overall, the results of the evaluation show that the CDG4E Game Creator, as well as the Fake News and STEM Education games were well received by students. Both games were able to spark interest in respective subjects, whereas students learned about the existence and importance of different species and the significance and consequences of media literacy.

\section{FURTHER RESEARCH}

The current Covid-19 situation has shown that new engaging and activating approaches in distant learning settings are needed and that frontal lectures are not the most suitable form of teaching online. Tools such as the CDG4E Game Creator allow tasks to be set by either the teacher or the student, then students can individually or collectively work on the solution (in this case creating a game on a specific topic) and finally the result is presented to other school mates and the teacher, followed by a reflection and or other debriefing activity. In addition, the created works can also be shared with friends and family and projects created in school go beyond the magic circle of the educational institution. However, since the tool presented here was developed, programmed and tested in the preCovid-19 period and is therefore optimized for use in the classroom, there is a lack of collaborative tools when using the CDG4E Game Creator as part of the didactical setup. Therefore, the consortium 
would like to take the next step and make the tool fit for use in times of a crisis like the Covid-19 situation and distance learning settings in general. Furthermore, based on the results of the evaluation, further projects aim at the improvement of the usability of the CDG4E Game Creator, the modernization of the design and the further development of new functionalities within an iterative design process. Last but not least, as with any educational tool, the commitment of teachers and students to use the tool to create and share games and teaching methods will play a crucial role.

\section{ACKNOWLEDGEMENTS}

The authors would like to thank EUPA for making this project possible under the Erasmus+ funding scheme.

\section{REFERENCES}

[1] Scratch, Accessed 14 September, 2020. Retrieved from https://scratch.mit.edu/

[2] Twine, Accessed 14 September, 2020. Retrieved from https://scratch.mit.edu/

[3] Pocket Code, Catrobat, Accessed 23 September, 2020. Retrieved from https://share.catrob.at/pocketcode/

[4] CDG4E Game Creator, Accessed 23 September, 2020. Retrieved from https://www.wazagames.com/gamecreator

[5] C. Fernandez-Vara, Introduction to Game-Analysis. London: Routledge, 2014

[6] T. Fullerton, Game Design Workshop: A Playcentric Approach to Creating Innovative Games, CRC press, 2014

[7] J. Schell, The Art of Game Design: A Book of Lenses, Oxford: Taylor \& Francis Ltd., 2014

[8] K. Salen, E. Zimmermann, Rules of Play: Game Design Fundamentals, Cambridge: the MIT Press, 2003

[9] J. Linderoth, B. Sjöblom, "Being an Educator and Game Developer: The Role of Pedagogical Content Knowledge in Non-Commercial Serious Games Production" in Simulation \& Gaming, vol. 50, no. 6, pp 771-788, 2019

[10] N. König, A. Pfeiffer, T. Wernbacher, N. Denk, "Game-Based Learning Research at the Danube University Krems' Center for Applied Game Studies." in Rediscovering Heritage Through Technology. Studies in Computational Intelligence (D. Seychell, A. Dingli, eds.), vol. 859, pp 123132, Cham: Springer, 2020, https://doi.org/10.1007/978-3-030-36107-5_7

[11] N. König, A. Pfeiffer, "Outputs and Insights From 12 Years of Game-Based Learning Research at the Danube-University Krems' Center for Applied Game Studies" in Proceedings of the 2019 Connected Learning Summit (J.H, \& D. Filipiak, eds.), vol. 1, pp 87-93, Pittsburgh: ETC Press, 2020, https://doi.org/10.1184/R1/11926884.v1

[12] N. Denk, A. Pfeiffer, T. Wernbacher, V. Camilleri, "Game Based Learning to Alleviate Early School Leaving" - Weiterentwicklung der Toolkit-GBL Plattform, zur Verringerung der Schulabbruchsquote in Malta und Schweden" in Game Based Learning - Dialogorientierung \& spielerisches Lernen analog und digital (J. Haag, J. Weißenböck, W. Gruber, C F. FreislebenTeutsche, eds.), Fachhochschule St. Pölten GmbH, 2015, Accessed 14 September, 2020. Retrieved from http://skill.fhstp.ac.at/wp-content/uploads/2016/05/Tagungsband_2015.pdf

[13] N. König, A. Pfeiffer, T. Wernbacher, „Gaming Media and Their Application in Educational Practice: An Interactive Toolkit for Teachers" in Proceedings of The 8th European Conference on Games Based Learning ECGBL 2014 (C. Busch ed.), vol. 1, pp 286-295, Berlin: Academic Conferences Ltd, 2014

[14] N. Denk, A. Pfeiffer, T. Wernbacher, B. Ertl, U. Röhsner, "A Social Network Game for Encouraging Girls to Engage in ICT and Entrepreneurship - findings of the project MIT-MUT" in Proceedings of the 3rd European Conference on Social Media (ECSM 2016) (C. Bernadas, M. Delphine edsl.), 63-70, Delphine, UK: Academic Conferences and Publishing International Limited Reading, 2016

[15] M. Overmars, GAME DESIGN IN EDUCATION, Accessed 12 September, 2020. Retrieved from http://webdoc.sub.gwdg.de/ebook/serien/ah/UU-CS/2004-056.pdf 
[16] M. Ahmad, "Categorizing Game Design Elements into Educational Game Design Fundamentals" in Game Design and Intelligent Interaction (I. Deliyanni, ed.), TechOpen, 2019, DOI: 10.5772/intechopen.89971

[17] P. Tan, "Iterative Game Design in Education", in International Journal of Arts and Technology (IJART), vol. 3, no. 1, 2010

[18] T. Bjoerner, C. B. Søgaard Hansen, "Designing an Educational Game: Design Principles from a Holistic Perspective" in The International Journal of Learning Annual Review, vol.17, np. 10, pp 279-290, 2011

[19] RPG Maker, Accessed 23 September, 2020. Retrieved from https://www.rpgmakerweb.com/

[20] Construct 3, Accessed 14 September, 2020. Retrieved from https://www.construct.net/en

[21] Game Maker Studio 2, Accessed 14 September, 2020. Retrieved from https://www.yoyogames.com/education

[22] Reigns, Devolver Digital, Accessed 23 September, 2020. https://reignsgame.com/reigns/ 